\title{
PENTECOSTALIDADE DA MISSÃO LATINO-AMERICANA: UMA NOVA REFORMA NA IGREJA? ${ }^{1}$
}

\author{
David Mesquiati de Oliveira ${ }^{2}$
}

\section{RESUMO}

O artigo versa sobre a influência do pentecostalismo na igreja protestante latino-americana. Parte do conceito de pentecostalidade para fundamentar uma tendência e princípio ordenador. $\mathrm{O}$ evento do Pentecostes está sendo revivido e reinterpretado. O Espírito é um só, o que promove comunhão e criatividade, através de sua obra criadora. Ele caracteriza a teologia pentecostal clássica e aponta elementos de uma missiologia pentecostal. Conclui identificandose com estudiosos que apontam o pentecostalismo como uma nova reforma na igreja. Essa reforma tem produzido diferentes formas de culto, pregação, liderança e de missão. O conceito de missão é apresentado como elemento existencial e identitário do pentecostalismo brasileiro.

\footnotetext{
${ }^{1}$ O tex to éuma adaptação da exposição "Missão: teoria e prática das igrejas pentecostais", feita pelo autor no Encontro entre luteranos e pentecostais ("Luther in Azusa Street"), realizada entre os dias 22/05-07/06/2011, na Universitát Leucorea, em Wittenberg, Alemanha, promovida pela Evangelische Kirche in Deutschland - EKD.

${ }^{2}$ David Mesquiati de Oliveira é bacharel em Economia (UFES) e Teologia (Faculdades EST), mestre em Teologia (Faculdades EST) e doutorando em teologia (PUCRio). Professor da Faculdade Unida de Vitória, pastor da Igreja Assembléia de Deus, foi missionário entre os quéchuas, na Bolívia, entre 2001 e 2005.
} 


\title{
PALAVRAS-CHAVE
}

Pentecostalismo; missão; Espírito Santo; Reforma.

\begin{abstract}
This essays deals with Pentecostal influence on Protestant Churches in Latin America. It builds up on the concept of Pentecostal Way of Life to ground both a tendency and an organizing principle. Nowadays, Pentecost event has been revived and reinterpreted. Holy Spirit is the Only One, and He promotes communion and creativity through His creative power. He also characterizes Pentecostal Theology and points out elements of a Pentecostal Theology of Mission. Scholars point out that Pentecostalism is a new Reformation of the Church, which has produced news forms of Worship, Preaching, Leadership, and Mission. This new form of Mission is an outstanding characteristic of Brazilian Pentecostalism.
\end{abstract}

\section{KEY-WORDS}

Pentecostalism, Mission, Holy Spirit, Reformation.

\section{Introdução}

Este artigo, em termos gerais, é uma reflexão sobre o plano da missão da igreja pentecostal. Chama a atenção na igreja latino-americana sua expressão religiosa, seu vigor eclesial e missionário, sua consciência de solidariedade e sua pertença popular. Mas não é somente uma religião popular (de massa). É marcado por um entusiasmo individual e comunitário que mais se aproxima dos tempos da igreja primitiva (César \& Shaull, 1999, p. 25). Vários estudiosos defendem estar ocorrendo uma pentecostalização da igreja. Onde é limitante? Que oportunidades apresenta? Reflito sobre a missão a partir de um ethos pentecostal e preciso assentar algumas bases comuns para que o diálogo com outros grupos cristãos possa ser frutífero. Reunirei algumas características do pentecostalismo e de sua teologia que impulsionam uma missão "em brasas" e concluirei com uma reflexão sobre alguns elementos de uma missiologia pentecostal latino-americana. 


\section{A pentecostalidade}

Parece adequado distinguir um elemento geral (a pentecostalidade) do pentecostalismo, que é a versão religiosa desse fenômeno, não permitindo que se restrinja a essa versão. $O$ teólogo pentecostal peruano Bernardo Campos afirma que o ser pentecostal deve ser compreendido também culturalmente, em manifestações de resistência político-religiosa. Seria necessário buscar uma relação entre esses pentecostalismos, de continuidade e ruptura (Campos, 1994, pp. 53s.). A pentecostalidade é "o princípio e a prática religiosa tipo informada pelo acontecimento (cristão) do Pentecostes. Esta 'intuição central' faz que a comunidade assim informada eleve a categoria de princípio (arque) ordenador e estruturante, a experiência primordial de Atos 2 e similares, e legitime e identifique suas práticas como prolongação daquela. Daqui a prática (pentecostalismos) e princípio ordenador e estruturante (a pentecostalidade) formam dois pólos diferenciáveis, mas mutuamente complementares" (Campos, 1994, pp. 55-56).

O teólogo católico Mario de França Miranda vê nessa pentecostalidade um princípio último de nosso relacionamento com Deus e entre nós. É o único Espírito, que todos recebemos, que constitui a unidade do corpo (1 Co 12.13). Nesse sentido o referido autor afirma que "todo cristão ou todo membro da Igreja é sem mais carismático" (Miranda, 2006, pp. 67-68).

Se as diferentes comunidades de fé (e confissões) romperem com esse princípio ordenador e estruturante, rompe-se também a continuidade com a Igreja una, santa, apostólica, proposta por Jesus. Onde estaria a diferença? Está justamente nas práticas que adotam. Cada grupo vai esforça-se para melhor aplicar e prolongar a lógica e a dinâmica da igreja neotestamentária. Esse exercício abre espaço para a contextualização e a criatividade.

O modo de ser pentecostal funde a realidade social com a espiritualidade, gerando uma re-significação do mundo e suas relações. Essa reinterpretação atualizou a experiência religiosa e possibilitou a adaptação da fé protestante do rural ao urbano na América Latina (Passos, 2001). O crescimento vertiginoso no século passado aponta para essa flexibilidade, nova linguagem e resposta atualizada da fé cristã. Por isso 
teve influência sobre o catolicismo e sobre as demais tradições cristãs, gerando igrejas renovadas. $\mathrm{O}$ pentecostalismo mostrou-se um corpo includente e foi favorecido pela crescente urbanização. Com o avanço da violência, exploração do trabalho e a fragmentação da sociedade, o pentecostalismo deu esperança, sentido, proteção, recompensas, libertação.

O sociólogo Edin Abumanssur afirma que "o pentecostalismo pode ser visto como uma estratégia de sobrevivência nas periferias das grandes metrópoles. Ao exigir de seus fiéis um comportamento mais austero e disciplinado, as igrejas pentecostais acabam por garantir uma menor exposição aos ambientes de violência das cidades" (Abumanssur, 2008, pp. 280-281). É o grupo religioso que mais exige mudança de hábitos de seus seguidores, com nova postura sobre bebida alcoólica, freqüentar bares e bailes, uso de tabaco, vestuário e como viver suas emoções. Sabem do ofício dos médicos, mas primeiramente fazem fervorosas orações antes de procurá-los. A mesma razão se aplica na pratica do exorcismo em indivíduos e localidades, que antecede o recorrer às ciências.

Quando o pentecostalismo surgiu no Brasil, em todo o país a realidade espiritual era outra. A Igreja Católica celebrava suas missas em latim; a Luterana, com a liturgia em alemão; a Anglicana, em inglês. O espiritismo ainda era caso de polícia e os cultos afros não eram nomeados ou reconhecidos. Oficialmente, não havia espaço para a religiosidade popular na época (Alencar, 2010). O idioma integrador do país é o português e ainda existiam centenas de culturas minoritárias, que não estavam sendo respeitadas ou não tinham voz.

A fé pentecostal reabilitou os leigos por meio da atualidade dos dons espirituais, transformando cada cristão em uma pessoa naturalmente engajada na causa do evangelho. A pentecostalidade contextualizada contribuiu também para recuperar a participação feminina - apesar de poucos grupos pentecostais atuais permitirem mulheres no ministério ordenado. No entanto, as mulheres passaram a ocupar um importante papel na vida congregacional no nascimento do movimento pentecostal. Atuavam voluntariamente em lideranças de grupos de oração, na assistência social, no uso dos dons espirituais, como educadoras infantis e na música. Como ministérios reconhecidos pelo corpo ofi- 
cial atuavam como diaconisas e como missionárias enviadas ao mundo, onde celebravam a Ceia, batizam nas águas e consagravam ministros. Outra contribuição fundamental das mulheres se deu na imprensa. Elas eram as principais articulistas dos jornais assembleianos nos anos 1920 e 1930. "Que outros jornais da época tinham mulheres como redatoraschefe? É uma vanguarda na questão de gênero que nenhum movimento feminista teve em qualquer parte do mundo", defende Gedeon Alencar (2010, p. 60).

A pentecostalidade gerou movimentos de revitalização da igreja, que passou a ser uma marca desse tempo e não pode ser minimizada no campo religioso-social. José Míguez Bonino afirma "porque o pentecostalismo é, quantitativamente, a manifestação mais significativa e, qualitativamente, a expressão mais vigorosa do protestantismo latinoamericano, seu futuro é decisivo não só para o protestantismo em seu conjunto, mas também para todo o campo religioso e sua projeção social." (Bonino, 2003, p. 70). Antonio Mendonça vai além e afirma (junto com a tese de Richard Shaull de que há uma nova Reforma a caminho) que a bandeira dessa nova Reforma é o Espírito Santo e o instrumento é o movimento pentecostal, afetando não só a igreja Católica, mas todas as igrejas cristãs tradicionais. (Mendonça, 1997, p. 175). A pergunta que cabe é: as igrejas estão se preparando para essa nova situação?

\section{Uma teologia pentecostal}

Isael de Araújo afirma que "a diversidade mundial do pentecostalismo torna quase impossível falar de 'uma' teologia pentecostal" (Araújo, 2007, p. 557). Contudo, é possível apontar alguns traços, sobretudo porque nos concentramos no pentecostalismo clássico ou histórico em terras brasileiras, representado em denominações como Assembléias de Deus e Congregação Cristã do Brasil (início do séc. 20). Teologicamente, os pentecostais se caracterizam pelo arminianismo e defendem o livre-arbítrio. Crêem na doutrina da Trindade, tendem a ser literais na interpretação bíblica e, freqüentemente, são marcados pelo dispensacionalismo. O elemento que distingue o pentecostalismo não é tanto o seu culto emotivo e expressivo, mas sua 
pneumatologia: o pentecostalismo insiste no batismo com o Espírito Santo como evento posterior à conversão e na atualidade dos dons espirituais (charismata). Por isso em suas reuniões terão um espaço reservado para orar por curas e por avivamento, com amplas manifestações de dons espirituais.

Os primeiros pentecostais no Brasil estavam encharcados de uma cultura avessa à academia teológica e ao denominacionalismo de origem. Tinham uma postura de sofrimento, martírio, contra-cultura e religião leiga: acostumados a marginalização, não tinham aspirações sociais (Freston, 1993, p. 91). Desprezavam a igreja estatal com seu alto status social e político e seu clero culto. Queriam algo prático e renovador. Não se preocuparam em tematizar essa experiência. Apenas em vivê-la. No afã de reviverem o pentecostes dos dias apostólicos, interpretam literalmente as experiências da Igreja Primitiva, trazendo-as para os dias atuais.

A doutrina do batismo com o Espírito Santo ensina que o cristão recebe um revestimento especial de poder para o exercício dos dons espirituais (Silva, 1996, p. 46). É preciso desejar esse "batismo" e viver uma vida piedosa. A finalidade é capacitá-lo sobrenaturalmente (Lc 24.49), transformá-lo em testemunha poderosa do evangelho (At 1.8) e unir o corpo de Cristo, derrubando barreiras e preconceitos (Ef 4.4). A evidência visível desse batismo é a glossolalia (falar em línguas estranhas, desconhecidas ou dos anjos). José Apolônio afirma que falar em outras línguas é uma das experiências pentecostais mais importantes e fundantes (Silva, 2004, p. 52). A glossolalia representa a oração no Espírito, a intercessão e o louvor. É diferente da xenolalia (falar em um idioma conhecido, estranho apenas a quem o fala). Os primeiros pentecostais achavam que este dom lhes seria útil para a evangelização dos povos, mas concluíram que se tratava de um dom para edificação da igreja e para uma vida de oração (Horton, 2006, p. 20).

Uma teologia pentecostal está dada pela relação intensa que desenvolve com o templo (alta freqüência), com a Bíblia (paixão pelas Escrituras, mormente lida e aplicada literalmente), com a atualidade dos dons espirituais (capacitação e sacerdócio de todos os crentes), com a escatologia (esperança de novo céu e do encontro com Cristo) e com a missão (anunciam em qualquer lugar e a todos). 


\section{Uma missiologia pentecostal}

O pentecostalismo latino-americano possibilitou o acesso às massas populares (Bonino, 2003, p. 53). Esse poder de penetração na sociedade é básico para uma missão contextualizada e relevante historicamente, aliado a um zelo evangelizador, que produz uma igreja militante. Sua missiologia é fortemente influenciada pela "Grande Comissão" (Mt 28.19; Mc 16.15) e pela noção de experiência especial com o Espírito Santo para ser testemunha em todo o mundo (At 1.8). É tarefa urgente, considerando as mazelas deste mundo e a condição de "perdidos" dos não-cristãos.

A igreja pentecostal entende a ekklesia literalmente. São chamados para fora do mundo (santificação) e para fora do seu grupo (evangelização). Por isso, abordam quem não pertence ao grupo com naturalidade, sendo acusados de proselitistas e conversionistas. A eficácia da evangelização depende, dentre outros fatores, da decisão do evangelizado em acolher ou não a proposta cristã. Os fiéis devem preocupar-se em anunciar com intrepidez o evangelho e vivê-lo de forma radical.

Percebo a missiologia assentada em três pilares: 1) ministério dos leigos, 2) apocalíptica e, 3) experiências com o Espírito Santo. Geremias do Couto afirma:

Somente a igreja que dispor de visão multiministerial (...) terá condições de estar presente em todas as circunstâncias que demandam sua ação na vida urbana. (...) Visão multiministerial significa diversidade de ministérios atuantes na igreja local para alcançar todos os segmentos sociais. Das crianças aos mais idosos, todos precisam estar mobilizados em todas as frentes - menores carentes, drogados, prostitutas, terceira idade, empresários, profissionais liberais, etc. - a fim de que se cumpra através da igreja o ministério da reconciliação (2 Co 5.18) (Couto, 2008, p. 417).

O sentido de privilégio e de urgência é fruto da visão apocalíptica. Os anjos quiseram anunciar o evangelho (1Pe 1.10-12), mas Deus reservou esse privilégio à sua igreja. É uma tarefa gigantesca e exige mordomia total (bens, talentos, dons, tempo, etc.) e urgência, pois a 
expectativa do retorno de Cristo é iminente. Evangelização é prioridade absoluta (Couto, 2008, p. 420) e a ênfase no poder do evangelho para libertar dos pecados e vícios é o que produz transformação social.

As experiências espirituais apontam para uma missão marcada por sinais miraculosos: a maioria dos grandes projetos missionários pentecostais começam a partir de reuniões de oração, onde buscam orientações através de sonhos, visões e revelações específicas. No diário de um dos pioneiros do pentecostalismo no Brasil, Gunnar Vingren, encontra-se o relato do seu chamado à missão em terras brasileiras. Foi "revelado" em um culto de oração o nome da cidade: Belém do Pará. No mesmo ano da visão (1911), ele chegou ao destino profetizado (Vingren, 2009, pp. 26s). O aspecto positivo dessa prática reside no fato das pessoas estarem abertas a experiências miraculosas e ao desenvolvimento de uma sensibilidade espiritual. Também ajuda nos momentos de indecisão e fraqueza, quando as dúvidas pairam sobre a condição de enviado às diferentes culturas. Contudo, pode ser muito negativa quando limita a espiritualidade à chamados missionários espetaculares. Além disso, depender de visões e sonhos pode ser perigoso, dado a subjetividade que os cerca.

Um elemento que está impactando negativamente as missões pentecostais é o chamado neopentecostalismo. Reação recente dentro do pentecostalismo, logo cedo rompeu com as bases do movimento. É marcado pela teologia da prosperidade, pelo comércio do sagrado, pela coisificação da religião e pela relação de clientela. Pelo intenso uso da mídia, do sensacionalismo e da manipulação, vários expoentes desse novo movimento estiveram no centro de grandes escândalos. Tal comportamento tem sido associado aos pentecostais (agora chamados de clássicos ou históricos) e tem contribuído para diminuir sua credibilidade e bom testemunho. A missiologia pentecostal tem se movido nesse campo minado, entre oportunidades e perigos. 


\section{Conclusão}

Assim, por ser fruto da experiência de Deus em cada membro, a missão pelos pentecostais é uma "missão em brasas". Recebe o sopro do Espírito inflamando cada membro da comunidade. Há um ardor missionário em cada cristão renovado, resgatando entre outros fatores, o ministério das mulheres. Participar da missio Dei é uma condição existencial. Sua flexibilidade (centram a pregação na fé individual e se organizam de maneira autônoma) permite sua rápida adaptação a diferentes contextos, pois tem uma forma de culto espontânea e informal. No século 21, nos defrontamos com uma nova Reforma, embalada por uma pentecostalidade e missiologia vivificada pelo Espírito Santo? Se for assim, sejamos inflamados pelo Espírito de Deus.

\section{Referências bibliográficas}

ABUMANSSUR, Edin S. Pentecostalismo e violência em São Paulo. In: SOTER (org.). Deus e vida. São Paulo: Paulinas, 2008, pp. 273-283. ALENCAR, Gedeon. Assembléias de Deus: origem, implantação e militância (1911-1946). São Paulo: Arte Editorial, 2010.

ARAÚJO, Isael de. Dicionário do movimento pentecostal. Rio de Janerio: CPAD, 2007.

BONINO, José M. Rostos do protestantismo latino-americano. São Leopoldo: Sinodal, 2003.

CAMPOS, Bernardo. Pentecostalismo y cultura. In: GUTIÉRREZ, Tomás. Protestantismo y cultura em América Latina. Quito: CLAI, 1994, pp. 51-68.

CÉSAR, W. \& SHAULL, R. Pentecostalismo e futuro das igrejas cristãs: promessas e desafios. Petrópolis: Vozes; São Leopoldo: Sinodal, 1999.

COUTO, Geremias do. Eclesiologia - a doutrina da igreja. In: GILBERTO, Antonio et alli. Teologia Sistemática Pentecostal. Rio de Janeiro: CPAD, 2008, pp. 379-440.

FRESTON, P. Protestantes e política no Brasil: da constituinte ao impeachment. Tese de doutorado. Campinas: Unicamp, 1993. 
HORTON, Stanley M. et all. Teologia sistemática: uma perspectiva pentecostal. 10 a ed. Rio de Janeiro: CPAD, 2006.

MENDONÇA, Antonio G. Protestantes, pentecostais \& ecumênicos. São Bernardo do Campo: UMESP, 1997.

MIRANDA, M. de França. A Igreja numa sociedade fragmentada: escritos eclesiológicos. São Paulo: Loyola, 2006.

PASSOS, João Décio. Teogonias urbanas: o renascimento dos velhos deuses. Tese de doutorado. São Paulo: PUC-SP, 2001.

SILVA, José A. da. Grandes perguntas pentecostais. $2^{\mathrm{a}}$ ed. Rio de Janeiro: CPAD, 2004.

SILVA, Severino P. da. A existência e a pessoa do Espírito Santo. Rio de Janeiro: CPAD, 1996.

VINGREN, Ivar. Diário do pioneiro Gunnar Vingren. $14^{\mathrm{a}}$ ed. Rio de Janeiro: CPAD, 2009. 